\title{
Os benefícios do mercado internacional de comércio de créditos de carbono para o Brasil
}

The benefits international trade market carbon credits for Brazil

\author{
Danielle Camila dos Santos ${ }^{1}$
}

\begin{abstract}
Resumo
Diante de um mundo que segue, desenfreadamente, as tendências consumistas em que o ser humano se esquece até mesmo de como manter sua própria vida, presenciamos estudiosos de todas as partes levantando suas vozes em prol de mudanças radicais em nosso ritmo de consumo e produção, e nos fazendo perceber que o mundo a nossa volta precisa voltar a ser saudável para que possamos viver. Surge nesses estudos um mecanismo chamado comércio de crédito de carbono que, a despeito das opiniões contrárias, poderá auxiliar tanto países com altas taxas de poluição como países em fase de desenvolvimento.
\end{abstract}

Palavras Chave: Meio Ambiente; Protocolo de Quioto; Comércio de Créditos de Carbono; Brasil.

\section{Abstract}

In a world that follows, wantonly, consumerist tendencies that humans forget how to keep even his own life, have seen scholars from all over raising their voices in favor of radical changes in our rate of consumption and production, and making us realize that the world around us needs to back to being healthy so we can live. Arises in these studies amechanism called trade in carbon credit that despite contrary opinions, may help both countries with high rates of pollution as coutries in development.

Keywords: Environment; Kyoto Protocol; Trade carbon credits; Brazil.

\section{Introdução}

A responsabilidade ambiental, mais do que um dever, é também um direito entre gerações. A Constituição Federal brasileira de 1988 estabelece que as presentes e as futuras gerações são as destinatárias da defesa e da preservação do meio ambiente. 0 relacionamento das gerações com o meio ambiente não pode se extinguir de imediato,

\footnotetext{
${ }^{1}$ Universidade Estadual de Londrina - Contato: daniellecamilafl@ hotmail.com
} 
impedindo que a população futura possa não ter condições de sobrevivência.

Desde o surgimento do ser humano sobre a face da Terra, o meio ambiente é que Ihe tem garantido, por intermédio de seus recursos, sua sobrevivência. Todavia, o mesmo homem nutrido e fortalecido por tais recursos provenientes deste ambiente passa a destruílo gradativamente chegando ao ponto em que se não parar, irá matar a si mesmo.

A partir do momento em que a humanidade foi integralmente sensibilizada das condições ambientais em que 0 mundo se encontra, passaram a ocorrer reuniões internacionais, como a exemplo a Convenção de 1972 em Estocolmo, a ECO-92 ou Conferência das Nações Unidas para o M eio Ambiente e o Desenvolvimento que aconteceu no Rio de Janeiro, em 1992 e o Protocolo de Quioto que ocorreu na cidade de mesmo nome, no Japão em 1997. Todas com o intuito de tentar solucionar as situações de perigo evidenciadas para o M eio Ambiente e a vida no Planeta.

Neste trabalho será apresentado especificamente o tema comércio de créditos de carbono, assim como se pretende destacar a necessidade, cada vez mais premente, da conscientização de cada um com o futuro do Planeta. Particulariza o mercado internacional de comércio de carbono, um mecanismo que se tornou famoso e que surgiu como forma de cumprir as proposições normativas advindas do Protocolo de Quioto, no qual se estabelece a comercialização dos créditos de carbono produzidos por meio do mecanismo de desenvolvimento limpo.

O objetivo do mecanismo de desenvolvimento limpo é a efetiva redução nas emissões dos chamados gazes de efeito estufa, preservando a integridade ambiental em todo o Planeta conforme as especificações estabelecidas pelo Protocolo de Quioto.

Para o Brasil essa pode ser uma forma promissora de garantir o desenvolvimento econômico, atraindo investimentos nacionais e internacionais para empresas que produzam sem agredir o meio ambiente, de forma que esta empresa conseguirá lucros com seus produtos e também com a venda dos créditos de carbono economizados durante a execução de sua produção.

Assim como há vantagens para a área empresarial brasileira, já que se supõe uma evolução social em razão da geração de empregos e circulação de capital, este instituto de venda de créditos de carbono ainda poderá auxiliar a área ambiental, criando novos mecanismos de defesa da Natureza, sendo ainda uma possibilidade de tornar real, as 
propostas elaboradas e ratificadas no Protocolo de Quioto, para que o mundo tenha uma chance a mais de ser recuperado e preservado.

\section{M eio ambiente}

A discussão sobre a expressão "meio ambiente" mostra a reflexão doutrinária sobre um tema de grande relevância para a humanidade e que exige esforço recorrente de todos no sentido de desvendar de forma integral os elementos que envolvem tudo que lhe diz respeito. Segundo o jurista de direito ambiental Toshio Mukai (2004, p. 5-6) ao trabalhar com o termo meio ambiente temos as seguintes definições:

\footnotetext{
- $\quad$ "Interação de elementos naturais, artificiais e culturais que propiciam 0 desenvolvimento equilibrado da vida do homem.

- $\quad$ Trata-se do homem (com seus problemas) ou de qualquer outro animal, ou vegetal, uma espécie viva, que insere-se em um tecido de co-ações entre os seres que ocupam o meio que os acolhe.

- $\quad$ É possível individualizar três sentidos para a expressão ambiente: como modo de ser global da realidade natural baseado num dado equilíbrio dos seus elementos; como soma de bens culturais; e, como ponto de referência objeto dos interesses e do direito urbanístico, respeitantes ao território como espaço.

- Ambiente é o conjunto dos sistemas físicos, químicos, biológicos e suas relações e dos fatores econômicos, sociais e culturais com efeito direto ou indireto, mediato ou imediato, sobre os seres vivos e a qualidade de vida dos homens.
}

A expressão meio ambiente como exposto possui variadas definições, para cada ramo em que é analisada, todavia aqui ela será trabalhada com preferência aos termos legais. O tema meio ambiente é tratado no Capítulo VI da Constituição Federal e em Leis Estaduais e Municipais, assim como doutrinas e jurisprudências.

A despeito dos conceitos e definições apresentados em muitos desses diplomas, a definição que mais vem sendo utilizada é a que se apresenta no artigo 3ㅇ, I da Lei que instituiu a Política Nacional do M eio Ambiente, Lei 6.938/81, cuja redação é idêntica a da a resolução do CONAM A no 306 de 2002, segundo os quais, entende-se por meio ambiente, “o conjunto de condições, leis, influências e interações de ordem física, química e biológica, que permite, abriga e rege a vida em todas as suas formas".

Em nossa Constituição Federal de 1988 o legislador, no capítulo VI, cuidou de criar um capítulo próprio para normas e regras referentes ao meio ambiente, mencionando sobre uma natureza totalmente avessa ao poder de criação humano além de identificar o meio 
ambiente artificial, fruto da cultura e do trabalho do homem, trazendo para o conceito meio ambiente novos elementos constitucionais.

Segundo Marcelo Abelha Rodrigues e Celso Antônio Pacheco Fiorillo, (2003, p. 5859), o meio ambiente se subdivide em natural, artificial, cultural e do trabalho. Os autores dissertam que: "o meio ambiente natural ou físico é constituído por solo, água, ar atmosférico, flora e fauna. Concentra o fenômeno da homeostase, que consistente no equilíbrio dinâmico entre os seres vivos e o meio em que vivem"

0 meio ambiente artificial é aquele que compreende o espaço urbano, as construções edificadas e os equipamentos públicos.

0 meio ambiente cultural de acordo com José Afonso da Silva (2000, p. 3) "é integrado pelo patrimônio histórico, artístico, arqueológico, paisagístico, turístico, que embora artificial, em regra, como obra do homem, tem sentido de valor especial"

\section{A defesa do meio ambiente no direito ambiental brasileiro}

Em todo o mundo, inclusive no Brasil, a real preocupação com o meio ambiente surgiu após a sucessão de várias tragédias ambientais que fizeram com que o homem percebesse que sua existência estava totalmente entrelaçada à existência saudável do planeta Terra.

É possível citar, a título de lembrança, as seguintes tragédias, o acidente na Baía de Minamata no Japão que foi provocado pelo despejo de efluentes industriais, sobretudo mercúrio; o acidente de Sevesco na Itália no ano de 1.976, na cidade italiana o superaquecimento de um dos reatores da fábrica de desfolhantes liberou densa nuvem que, entre outras substâncias, continha dioxina, produto químico muito venenoso. 0 acidente de Bhopal, na Índia em 1.984, em que houve uma falha no equipamento de uma empresa e ocorreu o vazamento de isocianato de metila, gás altamente venenoso que matou 3.300 pessoas, além de bois, cães e aves; 0 acidente na Basiléia na Suiça em 1.986 em que houve derramamento de agrotóxico no recurso hídrico; dentre vários outros.

Após a ocorrência destes e de outros tantos, em 1.972 ocorreu a Conferência sobre - Meio Ambiente Humano realizada em Estocolmo, que foi o ponto de partida dos movimentos ecológicos e também para a instituição de um estudo mais aprofundado dos direitos ambientais. 
Em matéria ambiental, nosso país iniciou desde sua época imperial a sancionar leis para resguardar o meio ambiente, contudo tratava-se de um cuidado voltado principalmente ao interesse patrimonial muito mais do que ambiental.

A primeira lei data de 1.635 , onde se criaram as primeiras Conservatórias, visando à proteção do pau-brasil. Em 1.797 foi assinada a primeira Carta Régia sobre a conservação das florestas e madeiras e no ano de 1.880 Dom João VI fundou o Jardim Botânico. Outra decisão importante ainda nos primórdios históricos foi quando Dom Pedro II em 1.861, mandou plantar a Floresta da Tijuca, com a finalidade de garantir suprimento de água para 0 Estado do Rio de Janeiro, uma vez que o abastecimento estava ameaçado pelo desmatamento das encostas dos morros.

Em datas mais contemporâneas, é válido trazer a baila que "desde o início o Brasil assumiu uma posição favorável a tese desenvolvimentista. 0 Embaixador Araújo Castro em julho de 1.970, salientou que os planos submetidos à Comissão Preparatória identificavamse com os problemas e as preferências dos países industrializados e não levavam em consideração as necessidades e condições dos países em desenvolvimento" (SILVA, 1995, p. 27).

Representantes brasileiros também estiveram presentes na Conferência de 1.972 em Estocolmo apoiando essa iniciativa em favor da vida do ambiente, ainda que a posição do governo militar da época fosse radicalmente favorável ao desenvolvimento a qualquer custo ambiental.

Em 1.992 no Rio de Janeiro ocorreu a ECO-RI092, Conferência das Nações Unidas para o Meio Ambiente e o Desenvolvimento, da qual decorreu a Declaração do Rio de Janeiro de 1.992 que preconizou a importância da realização do estudo de impacto ambiental, afirmando em seu Princípio 17: "A avaliação de impacto ambiental, como instrumento nacional, deve ser empreendida para atividades planejadas que possam vir a ter impacto negativo considerável sobre o meio ambiente, e que dependam de uma decisão de uma autoridade nacional competente".

O Brasil, em 1981, com a Lei n. 6.938/1981, já havia adotado em sua legislação esse emergente instrumento jurídico de prevenção do dano ambiental, que foi, posteriormente, confirmado pela Constituição Federal de 1.988 diz no artigo 225, § o, inciso IV: 
Art. 225. Para assegurar a efetividade desse direito, incumbe ao Poder Público:

$[\ldots]$

IV - exigir, na forma da lei, para instalação de obra ou atividade potencialmente causadora de significativa degradação do meio ambiente, Estudo Prévio de Impacto Ambiental, a que se dará publicidade. (BRASIL, 1988)

De acordo com nossa lei constitucional, percebe-se desde logo a preocupação de que todas as obras e todas as atividades que possam causar degradação significativa ao meio ambiente devem ser devidamente analisadas. A palavra potencialmente abrange não só 0 dano de que não se duvida como 0 dano incerto e o dano provável.

No Brasil, a Lei 6.938/81, em seu art. 20 estabelece, em sua política nacional do meio ambiente, que sempre se observará os princípios da "proteção dos ecossistemas, com a preservação das áreas representativas", e "a proteção de áreas ameaçadas de degradação", pois não é condizente proteger sem aplicar medidas de prevenção.

A Constituição Federal também trouxe ao bojo social, pela primeira vez, o tema "meio ambiente", atribuindo-Ihe concepção unitária. A Magna Carta de 1.988 passou a garantir o "direito de todos ao meio ambiente ecologicamente equilibrado e essencial à sadia qualidade de vida", em seu artigo 225 e seus parágrafos. Além disso, conceitua o meio ambiente como 'bem de uso comum do povo' e, dessa forma, não é passível de apropriação patrimonial e é extracomércio". (MACHADO, 2004, p. 98)

Ao tratar o meio ambiente como um direito de 'todos', o legislador generaliza a norma constitucional dando a todos o direito a esse bem evitando que se exclua qualquer pessoa, e ao afirmar que 'todos têm direito', se cria um direito subjetivo, erga omnes.

"O meio ambiente é um bem coletivo de desfrute individual e geral ao mesmo tempo. Há um o direito ao meio ambiente para cada pessoa, mas não é exclusivamente dela, sendo igualmente transindividual". (M ACHADO, 2004, p. 121)

Por isso, o direito ao meio ambiente entra na categoria de interesses difusos, não se esgotando a uma só pessoa, mas cabendo a uma coletividade indeterminada.

Como se verificou a doutrina entende que a proteção patrimonial do meio ambiente existe desde os primórdios de sua história, todavia a ciência autônoma conhecida como Direito Ambiental e a proteção e garantia aos direitos inerentes ao tema ainda é nova em relação a outras ciências jurídicas, uma vez que seus marcos principiológicos estão determinados no século XX, com as Conferência de Estocolmo e do Rio de Janeiro. 
Essa nova temática jurídica é considerada como sendo o conjunto de princípios reguladores da atividade humana que afetam a sanidade do ambiente em sua dimensão total, com o objetivo de gerar sustentabilidade e a efetivação de vida para as presentes e futuras gerações. (MILARÉ, 2004, p. 134)

\section{Gás carbônico como fonte do aquecimento global}

O carbono, principal causador do efeito estufa, é um elemento químico que se encontra em diversas atividades ecológicas da Terra há milhares de anos. A maioria dos compostos químicos existentes na atmosfera terrestre tem carbono em sua composição.

A partir da revolução industrial, que ocorreu na Inglaterra no século XVIII, enormes quantidades do elemento químico carbono, devido à queima de combustíveis fósseis para 0 funcionamento das empresas, foram expelidas para atmosfera sob a forma de gás carbônico, o que desencadeou uma série de conseqüências decorrentes do efeito estufa e resultando em um fenômeno atualmente conhecido no mundo inteiro como aquecimento global, responsável pelos distúrbios ambientais.

De acordo com o artigo publicado pela escritora Sarah Dowdey (2007) o Painel Internacional de M udanças Climáticas, entre os anos de 1.980 e 1.998, houve um aumento de $65 \%$ das emissões de gás carbônico no planeta.

As plantas, por sua vez, no seu processo de fotossíntese, não mudaram suas condições físico-químicas de absorver todo o montante disponível, mantendo seu potencial de absorção do gás carbônico ao mesmo nível de sempre. Merece, ainda, lembrar que 0 aumento de emissão de gás carbônico aconteceu ao mesmo temo em que o número de florestas e matas foi diminuindo, também pela ação humana.

Com todas essas mudanças, foi necessária a intervenção internacional para tentar modificar essas condições caóticas. Nesse sentido o surgimento do Protocolo de Quioto, como uma evolução da Convenção Quadro sobre Mudanças Climáticas, expressa a preocupação mundial com a necessidade premente de intervir na situação do clima com o objetivo de tentar reverter este cenário crítico. 


\section{Protocolo de Quioto como mecanismo de defesa do clima e do meio ambiente}

O Protocolo de Quioto é um tratado internacional que foi redigido na cidade de Quioto no Japão em 1.997 e teve sua abertura para assinatura em 16 de março de 1.998, sendo que só poderia entrar em vigor 90 dias após a sua ratificação por pelo menos 55 das Partes da Convenção, incluindo os países desenvolvidos que contabilizaram pelo menos 55\% das emissões totais de dióxido de carbono.

O Protocolo de Quioto tem como fundamento principal a redução da emissão de gases causadores do efeito estufa que tem como maior conseqüência para o planeta e para a vida terrestre, o aquecimento global, causador dos desequilíbrios ambientais ocorridos habitualmente.

0 documento apresenta em seu conteúdo, diretrizes gerais para amenizar os problemas ambientais causados pelos impactos ecológicos provocados principalmente pelo avançado e destrutivo desenvolvimento industrial e pelo consumismo desenfreado, onde quase tudo é simplesmente descartável e ainda mesmo tendo utilidade acaba virando lixo. A principal diretriz é a redução das emissões de gás carbônico em 5,2\% de acordo com os níveis do ano de 1.990, pelos países desenvolvidos até 0 ano de 2.012 .

Estes países desenvolvidos segundo classificação do próprio Protocolo são chamados de países do Anexo 1. São eles, Alemanha, Austrália, Áustria, Bélgica, Bulgária, Canadá, Dinamarca, Eslováquia, Espanha, Estados Unidos da América, Estônia, Federação Russa, Finlândia, França, Grécia, Hungria, Irlanda, Islândia, Itália, Japão, Letônia, Liechtenstein, Luxemburgo, Mônaco, Noruega, Nova Zelândia, Países Baixos, Polônia, Portugal, Reino Unido da Grã Bretanha e Irlanda do Norte, Republica Checa, Romênia, Suécia e Suíça.

O Protocolo de Quioto, que na verdade é um desdobramento da Convenção Quadro sobre M udanças Climáticas realizada durante a ECO-RI092 no Rio de Janeiro, institui que os países pertencentes ao grupo do Anexo I devem procurar limitar ou reduzir as emissões de gases do efeito estufa e devem empenhar-se em implementar políticas e medidas de forma a minimizar efeitos adversos da mudança do clima, os efeitos sobre o comércio internacional e os impactos sociais, ambientais e econômicos sobre outros países, especialmente países em desenvolvimento, além de buscar formas alternativas de energia, eliminando o uso de combustíveis fósseis. 
Tais países, devem individual ou conjuntamente, assegurar que suas emissões não excedam suas quantidades atribuídas, calculadas em conformidade com seus compromissos quantificados de limitação e redução de emissões, além de realizar um progresso comprovado para alcançar os compromissos assumidos sob este Protocolo.

Em 2.012 o Protocolo de Quioto irá expirar, fazendo com que legisladores e profissionais ligados ao meio ambiente de todos os países do mundo procurem analisar as realizações e as deficiências deste documento com o fim de melhorá-lo, estipulando novas metas e prazos para obter resultados melhores.

\section{Mercado internacional de créditos de carbono para o Brasil}

O Protocolo de Quioto, ao instituir que os países deveriam reduzir sua emissões de dióxido de carbono e outros gases causadores do efeito estufa para se mitigar os problemas ambientais, não descreveu em seu texto o modo como os membros do Anexo 1 deveriam concretizar a redução dessas emissões, deixando a critério de cada país poluidor o direito de administrar da maneira como julgar melhor para alcançar as metas estabelecidas. Em resposta a essa discricionariedade nasceram diversas formas de se proporcionar diminuição de emissão de gases.

A maior e mais famosa é o Esquema de Comércio Europeu (European Trading Scheme - ETS), também chamado de Comércio de Carbono, Mercado Internacional de Comércio de Créditos de Carbono, onde seu esquema multisetorial consiste em limitar a produção de gases e negociar esse crédito internacionalmente em uma bolsa de valores.

Dentro deste mercado internacional de comércio de créditos de carbono, cada país pertencente ao grupo do Anexo 1, que ratificou o Protocolo de Quioto, tem a autonomia de poder fixar seu próprio limite de emissões, obedecendo a metas estabelecidas no documento ratificado.

Todavia, como em quase todas as inovações o comércio de créditos de carbono gera questionamentos, sobre seu real auxilio quanto à redução das emissões de gases nocivos ao meio ambiente. Alguns chegam a debater a idéia de que essa chance de comercializar créditos de carbono, na verdade, seria mascarar uma conduta de permissividade, ou seja, uma simples 'permissão para poluir', dada aos países desenvolvidos, 
porque esse tipo de comércio se baseia em distribuição de licenças livres de encargos dada a empresa, sem que se faça uma devida verificação das reduções.

As empresas financiadas nos países subdesenvolvidos ou em desenvolvimento podem apresentar projetos que ajudem a diminuir as emissões de carbono, como, por exemplo, uma fábrica que usa carvão vegetal e passa a usar uma fonte energética mais limpa ou que absorva carbono como os projetos de reflorestamento. Financiando estes projetos, os países do Anexo 1 ganham créditos de redução certificadas de emissões para adicionar as suas próprias licenças.

\section{Benefícios ao mercado internacional decorrentes do comércio de créditos de carbono}

No Brasil, algumas empresas já vêm se adaptando às tendências desse novo mercado, especializando-se em elaborar projetos de política de carbono, acreditando ser esse um mercado promissor.

0 comércio de créditos de carbono tem movimentado os departamentos financeiros e ambientais de várias empresas brasileiras. Em setembro de 2007, 0 Brasil já possuía 61 empresas com créditos emitidos pela ONU. São 11,3 milhões de toneladas de $\mathrm{CO}^{2}$ que deixam de ir para a atmosfera. Não há um número fechado para o volume já negociado, mas as estimativas giram em torno de 90,4 milhões de euros ou R\$ 240 milhões (DOWDEY, 2011).

São grandes empresas, como, por exemplo as de papel e celulose, usinas de açúcar, madeireiras ou fábricas em geral (DOWDEY, 2011).

A Prefeitura de São Paulo também deu um passo em direção a este mercado e sua futura benesse. $\mathrm{Na}$ administração paulistana se leiloa créditos de carbono advindos do projeto do aterro Bandeirantes.

Aconteceu em São Paulo, o primeiro de leilão de créditos de carbono do mundo, obedecendo a normas oriundas de mecanismo de desenvolvimento limpo. "O banco holandês Fortis Bank NV/SA pagou 34 milhões de reais por 808.450 créditos de carbono colocados em negociação pela Prefeitura de São Paulo na Bolsa de Mercadorias e Futuros em 26 de setembro de 2.007." (DOWDEY, 2011).

Acredita-se que o Brasil possa chegar a movimentar cerca de 500 milhões de reais 
ao ano neste mercado internacional de créditos de carbono.

Referente ao governo do Estado de Santa Catarina, em 30 de novembro de 2.007, este assinou um contrato de adesão com a Bolsa de Clima de Chicago, sendo a primeira instituição pública da América Latina a entrar no mercado voluntário de créditos de carbono americano. 0 Estado catarinense pretende compensar suas emissões de gás carbônico de um período que vai de 1.985 a 2.007. (DOWDEY, 2011).

A prática da comercialização de créditos de carbono traz grandes lucros, além de ampliar a áreas de conservação ambiental e modernizar a temática de normas jurídica quanto ao tema, posto que o lucro proporcionado por este mercado faz com que o pais, além da entrada de capital, passe a investir em mecanismos de desenvolvimento limpo $M D L$.

Segundo Luiz Aroeira (2011) o Brasil deve se beneficiar desse cenário de venda de créditos de carbono, como receptor de investimentos em projetos engajados em redução de emissão de gases poluentes, como, por exemplo, o projeto de desenvolvimento do biodiesel.

Segundo o mesmo autor, o País possui mais de 231 projetos de mecanismos de desenvolvimento limpo, o que significa dizer que o Brasil não emite por meios desses institutos 204.314.584 toneladas de gás carbônico e outros gases poluentes.

Os projetos de mecanismos de desenvolvimento limpo abrangem aterros sanitários, uso de biomassa para produção de álcool, uso de energia eólica, substituição do combustível fóssil por energias provenientes de fontes renováveis, preservação das áreas florestais e incentivo ao reflorestamento.

\section{Conclusão}

Diante das constantes mudanças pelas quais nosso Planeta tem passado passamos a nos preocupar em valorizar a vida e pensar sobre nosso futuro e de todos os seres vivos. As mudanças ambientais ocorridas em razão da ação humana, de suas atividades e dos danos provocados, culminaram com uma série de respostas da natureza que surpreenderam a humanidade. Estamos presenciando a fúria da natureza em resposta ao descuidado humano.

0 Brasil tem uma Constituição Federal considerada cidadã. 0 texto basilar, que estabelece o caminho norteador dos mecanismos de controle traçados pelo Estado em prol do meio ambiente, sem descuidar do desenvolvimento econômico e social, aponta para 
diversos temas ligados ao meio ambiente com princípios norteadores que embasam 0 ordenamento.

A Constituição Federal brasileira de 1.988 trouxe responsabilidade conjunta ao Poder Público e à coletividade como agentes fundamentais na ação defensora e preservadora do meio ambiente, fazendo com que todos assumissem sua parcela de responsabilidade neste compromisso comum.

Em âmbito internacional ocorreram e vem ocorrendo discussões em convenções e encontros que resultam em tratados internacionais que absorveram os ideais transformadores em prol da preservação, destacando-se o Protocolo de Quito, com sua função de tentar minimizar as emissões de gás carbônico para suprimir os efeitos do aquecimento global que, segundo os cientistas, gera demasiado descontrole ambiental a ponto de desencadear fenômenos como tornados, tsunamis, chuvas ácidas, estações indefinidas, entre outros fatores que demonstram a total "insatisfação" do M eio Ambiente com seus habitantes humanos.

Este documento, que também foi ratificado pelo Brasil, permitiu a consecução de propostas mitigadores que representaram ganhos econômicos, sobretudo, aos países em desenvolvimento, por intermédio da comercialização de créditos de carbono, confirmando o princípio de reduzir e vender.

Com este programa, países poluidores passam a investir em projetos ligados aos mecanismos de desenvolvimento limpo com o objetivo de reduzir o percentual de suas emissões de gases nocivos a vida. Tais investimentos devem ser realizados em países subdesenvolvidos ou países em desenvolvimento.

O Brasil passou a investir nesse ramo que parece ser promissor. Nossos empresários e até órgãos públicos investem em criação de projetos de desenvolvimento limpo, seja com redução de emissão ou com investimento em preservação e reestruturação ambiental.

Tal forma de comercialização é tão inovadora que ainda não possui um quadro completo de normas jurídicas para regulamentação. Contudo, mecanismos de controle do Estado, colocados a postos com princípios específicos que identificam o Direito Ambiental, tanto na esfera interna com internacional se encarregam de estipular diretrizes a serem seguidas por todos esses órgãos econômicos e públicos que pretendem alcançar as metas estabelecidas pelo Protocolo de Quioto. 


\section{Referências}

AROEIRA, Luiz. Créditos de carbono no Brasil. Disponível em:

বhttp://www.planetaorganico.com.br/creditocarbono-aroeira.htm>. Acesso em: 20 ago. 2011.

BRASIL. Constituição (1988). Constituição da Republica Federativa do Brasil de 1988. 1988. Disponível em: $\diamond$. Acesso em: 20 ago. 2011.

DOWDEY, Sarah. Como funciona o comércio de carbono. 2007. Disponível em: বhttp://empresasefinancas.hsw.uol.com.br/comercio-de-carbono.htm>. Acesso em: 20 ago. 2011.

M ACHADO, Paulo Affonso Leme. Direito ambiental brasileiro. 12. ed. São Paulo: Malheiros, 2004.

M ILARE, Edis. Direito do Ambiente. 5 ed. São Paulo: Revista dos Tribunais, 2004.

MUKAI, Toshio. Direito ambiental sistematizado. 4. ed. Rio de Janeiro: Forense Universitária, 2004.

RODRIGUES, Marcelo Abelha; FIORILLO, Celso Antônio Pacheco. Manual de direito ambiental. São Paulo: M alheiros, 2003.

SILVA, Geraldo Eulálio do Nascimento e. Direito ambiental internacional. Rio de Janeiro:

Thex, 1995.

SILVA, José Afonso da. Direito ambiental constitucional. São Paulo: Malheiros, 2000.

Artigo recebido em:

26 ago. 2011

Artigo aprovado em:

10 nov. 2011 